\title{
Treatment of Diabetic Ketoacidosis (DKA)/Hyperglycemic Hyperosmolar State (HHS): Novel Advances in the Management of Hyperglycemic Crises (UK Versus USA)
}

\author{
Ketan K. Dhatariya ${ }^{1,3} \cdot$ Priyathama Vellanki $^{2}$ \\ Published online: 31 March 2017 \\ (C) The Author(s) 2017. This article is published with open access at Springerlink.com
}

\begin{abstract}
Purpose of Review Diabetic ketoacidosis (DKA) and hyperglycemic hyperosmolar state (HHS) are diabetic emergencies that cause high morbidity and mortality. Their treatment differs in the UK and USA. This review delineates the differences in diagnosis and treatment between the two countries. Recent Findings Large-scale studies to determine optimal management of DKA and HHS are lacking. The diagnosis of DKA is based on disease severity in the USA, which differs from the UK. The diagnosis of HHS in the USA is based on total rather than effective osmolality. Unlike the USA, the UK has separate guidelines for DKA and HHS. Treatment of DKA and HHS also differs with respect to timing of fluid and insulin initiation. Summary There is considerable overlap but important differences between the UK and USA guidelines for the management of DKA and HHS. Further research needs to be done to delineate a unifying diagnostic and treatment protocol.
\end{abstract}

Keywords Diabetic ketoacidosis · Management · Survey · Hyperglycemic hyperosmolar state

This article is part of the Topical Collection on Hospital Management of Diabetes

Ketan K. Dhatariya

ketan.dhatariya@nnuh.nhs.uk

1 Elsie Bertram Diabetes Centre, Norfolk and Norwich University Hospitals NHS Foundation Trust, Colney Lane,

Norwich, Norfolk NR4 7UY, UK

2 Division of Endo, Metabolism \& Lipids, Emory University School of Medicine, Atlanta, GA, USA

3 University of East Anglia, Norwich Research Park, Norwich NR4 7TJ, UK

\section{Introduction}

Diabetic ketoacidosis (DKA) and hyperglycemic hyperosmolar state (HHS) are hyperglycemic emergencies that continue to account for increased burden of hospitalizations in both the USA [1] and UK [2]. Historically, both DKA and HHS were initially described as one entity but subsequently recognized as separate conditions. Since the advent of insulin, mortality has fallen for DKA and HHS, but the risk remains high. Previous work from the UK and seminal randomized controlled studies performed in the USA by Abbas Kitabchi form the basis of treatment of DKA and HHS. However, only a few of these were randomized studies to guide clinicians on the best way to manage DKA and HHS. Whilst the principles are well known-fluids, insulin, and electrolytes, the questions remain about how much, how fast, etc. This lack of a firm evidence base has led to these small differences in management in both the USA and UK. Additional factors, such as the healthcare environment, also have an impact. In this article, we will discuss the main differences between the USA and UK in the treatment of DKA and HHS.

\section{Diabetic Ketoacidosis}

Prior to the discovery and isolation of insulin in 1922 by Banting and Best, type 1 diabetes was universally fatal within a few months of initial diagnosis. Once mass production was started, the challenge to those early pioneers of insulin treatment was learning how to use this new wonder drug, e.g., how much to give and how often to give it, in order to treat the hyperglycemia without raising the inherent risk of hypoglycemia. 
In 1945, Howard Root in Boston described how they had improved the outcomes for people with diabetic ketoacidosis (DKA), reducing mortality to $12 \%$ by 1940 and to $1.6 \%$ by 1945 using high doses of insulin — giving an average of 83 units within the first $3 \mathrm{~h}$ of treatment in 1940 and 216 units by 1945 [3]. They described how in 1945, they used an average of 287 units in the first $24 \mathrm{~h}$, but this ranged from 50 to 1770 units [3]. In Birmingham, UK, high-dose insulin was also being used with similar success - doses varying depending on the degree of consciousness, with those unarousable on admission given doses between 500 and 1400 units per $24 \mathrm{~h}$ [4]. DKA remains a medical emergency; over time, mortality has continued to fall but remains a significant risk, especially amongst the young, socially isolated and when care provision is fragmented $[5 \bullet, 6 \bullet]$. Overall, the diagnosis and treatment of DKA are very similar in the UK and USA with a few differences. The UK has separate guidelines on the management of DKA [7], while the USA has a position statement on DKA and HHS that was updated in 2009 [8]. The UK guideline differs in several ways from the US position statement.

The concept of low-dose intravenous insulin was established in the late 1960 s and early 1970 s by teams on both sides of the Atlantic. The UK championed the use of insulin infusions of between 1.2 and 9.6 units per hour at a fixed rate [9-11]. In the USA, Kitabchi et al. used a variety of low-dose insulin regimens, e.g., 0.22 units per kilogram (with a subsequent sliding scale dependent on subsequent glucose concentrations) or 0.33 units per kilogram followed by an infusion of 7 units per hour $[12,13]$. These regimens led to a steady reduction in glucose and ketone concentrations at a rate comparable to the higher insulin doses [9-11]. This then led the way to weight-based, fixed-rate intravenous infusion rates [7, 14]. Kitabchi and colleagues went on to do some seminal work looking at the effects of electrolyte disturbances, including the effects of bicarbonate use in DKA. Their significant contributions to the field have been highlighted elsewhere [15].

There are few randomized studies to guide clinicians on the best way to manage DKA. Whilst the principles are well known-fluids, insulin, and electrolytes, the questions remain about how much, how fast, etc. This lack of a firm evidence base has led to these small differences in management. Additional factors, such as the healthcare environment, also have an impact. In the UK, there is the principle of universal health coverage, where payment for healthcare is deducted from income tax and care is provided free at the point of delivery. In the USA, a predominantly insurancebased system exists. In those who have no insurance or minimal health insurance coverage, it would be important to consider ways or providing safe and appropriate treatment that is affordable for the patient and the caregivers. This comparison between the two ways of treating DKA is the focus of this article.

\section{Differences in Diagnosis}

Unlike the USA, the UK has separate guidelines on the management of DKA and HHS [16, 17]. These differ in several ways from the US position statement on hyperglycemic emergencies in adults authored by Kitabchi et al. that was last updated in 2009 [8].

\section{DKA-Diagnosis}

There are differences in the diagnostic criteria for DKA between the UK and the USA (Table 1). There are several potential implications of these differences. The UK criteria suggest that you either have DKA or you do not. But, both documents state that the diagnosis can only be made when all three criteria (the "D," the "K," and the " $A$ ") are present. The cornerstone of treatment is administration of fluids and insulin with the endpoint of decreasing ketogenesis.

\section{The UK Perspective}

The UK guideline states that to make a diagnosis of DKA, a prior history of diabetes, regardless of glucose concentrations, although (a glucose $>11 \mathrm{mmol} / \mathrm{L}$ (200 $\mathrm{mg} / \mathrm{dL}$ ) is specified), is sufficient diagnostic criteria. Due to the availability of testing of 3-beta-hydroxybutyrate testing at the bedside, measurement of serum ketones with a level $>3 \mathrm{mmol} / \mathrm{L}$ has been suggested as part of the diagnostic criteria for ketoacidosis as opposed to using the urine ketones. Also, the UK guidelines state that using venous blood gas rather than arterial blood gas with a $\mathrm{pH}<7.3$ should be used for diagnosis of acidosis.

There are several advantages to the UK criteria. Approximately $10 \%$ of patients with DKA present with euglycemic DKA [18] or with glucose levels below the thresholds set by the US guidelines. This is a condition that is becoming more of an issue with the recognition that it can occur in people taking sodium glucose co-transporter 2 inhibitors [19•] and in pregnancy [20]. Therefore, the emphasis on the history of previous diabetes with a lower glucose threshold than the US criteria allows for detection of euglycemic ketoacidosis. The use of serum rather than urine ketones is advantageous. People with DKA are usually dehydrated, and thus, urine output is low; it may be several hours before urine is produced, further delaying the instigation of appropriate management. Any estimation of urine ketones collected in this way will be an average of the concentration within the urine held in the bladder since the last void. Finally, as the DKA resolves, $\beta$-hydroxybutyrate is converted to acetoacetate, which is then excreted into the urine, giving the (false) impression that the condition is taking longer to resolve that it actually is. For these reasons, urine ketone testing is not routinely recommended in the UK guideline. However, because point-of-care, bedside blood ketone meters are not universally 
Table 1 UK vs USA diagnostic criteria for DKA

\begin{tabular}{|c|c|c|c|c|c|}
\hline & & \multirow[t]{2}{*}{ UK } & \multicolumn{3}{|l|}{ USA } \\
\hline & & & Mild & Moderate & Severe \\
\hline \multicolumn{2}{|l|}{$\begin{array}{l}\text { "D" - a glucose } \\
\text { concentration }\end{array}$} & $\begin{array}{l}>11.0 \mathrm{mmol} / \mathrm{L}(200 \mathrm{mg} / \mathrm{dL}) \\
\quad \text { or a previous history of } \\
\text { diabetes mellitus }\end{array}$ & $\begin{array}{l}>13.9 \mathrm{mmol} / \mathrm{L} \\
\quad(>250 \mathrm{mg} / \mathrm{dL})\end{array}$ & $\begin{array}{l}>13.9 \mathrm{mmol} / \mathrm{L} \\
\quad(>250 \mathrm{mg} / \mathrm{dL})\end{array}$ & $\begin{array}{l}>13.9 \mathrm{mmol} / \mathrm{L} \\
\quad(>250 \mathrm{mg} / \mathrm{dL})\end{array}$ \\
\hline \multicolumn{2}{|l|}{$\begin{array}{l}\text { "K"-the presence } \\
\text { of ketones }\end{array}$} & $\begin{array}{l}>3.0 \mathrm{mmol} / \mathrm{L} \text { or significant } \\
(>2+) \text { on standard urine } \\
\text { ketone sticks }\end{array}$ & $\begin{array}{l}\text { Urine or serum } \\
\text { ketone positive }\end{array}$ & $\begin{array}{l}\text { Urine or serum } \\
\text { ketone positive }\end{array}$ & $\begin{array}{l}\text { Urine or serum } \\
\text { ketone positive }\end{array}$ \\
\hline \multirow{3}{*}{$\begin{array}{l}\text { "A" - confirmation } \\
\text { of an acidosis }\end{array}$} & $\mathrm{pH}$ & $<7.3$ & 7.25 to 7.30 & 7.00 to $<7.24$ & $<7.00$ \\
\hline & $\begin{array}{l}\text { Serum bicarbonate } \\
\quad(\mathrm{mmol} / \mathrm{L})\end{array}$ & $<15$ & 15 to 18 & 10 to $<15$ & $<10$ \\
\hline & Anion gap & Not applicable & $>10$ & $>12$ & $>12$ \\
\hline
\end{tabular}

Adapted from $[7,8]$

available in all hospitals at all times, there is provision made to allow for the occasional use of urine ketones [16, 21••]. The use of venous $\mathrm{pH}$ is recommended for the diagnosis of acidosis, because of the data suggesting that the differences between arterial and venous $\mathrm{pH}$ are not large enough to change clinical management decisions [22-25]. Furthermore, the anion gap is not used as part of the diagnosis of DKA in the UK. This is in part because a serum chloride is neither routinely reported as part of the blood gas analysis, nor reports of electrolyte concentrations. In addition, the use of $0.9 \%$ sodium chloride solution can cause a hyperchloremic metabolic acidosis, and the persistent rise in serum chloride can give the impression to those who are unwary or inexperienced that the resulting high anion gap could be due to the persistent presence of ketones, rather than being due to the fluid resuscitation.

\section{The US Perspective}

The US guidelines suggest using a glucose threshold of $>250 \mathrm{mg} / \mathrm{dL}$ (13.9 mmol/L), presence of positive serum and urine ketones with an anion gap, and arterial $\mathrm{pH}<7.3$ to make the diagnosis of DKA. The biggest difference between the UK and the US guideline is the classification of the severity of DKA (Table 1). There are several advantages to categorizing DKA according to severity.

The American Diabetes Association (ADA) consensus guidelines recommend assessment of severity of DKA based on mental status along with the laboratory parameters. While the ADA guidelines acknowledge that approximately $10 \%$ of patients with DKA present with lower glucose levels, they emphasize that the key diagnostic feature of DKA is elevated ketonemia. The reasons for dividing DKA presentation into different levels of severity are multifactorial. One of the reasons is due to availability of resources. In the UK, there is the principle of universal health coverage, where payment for healthcare is deducted from income tax and care is provided free at the point of delivery. In the USA, a predominantly insurance-based system exists. In those who have no or minimal health insurance coverage, it would be important to consider ways or providing safe and appropriate treatment that is affordable for the patient and the caregivers. The ADA guidelines also suggest that mental status be used to grade severity. This particular emphasis allows for safer triage of patients presenting to the emergency room to either the intensive care units or step-down units. Further, as per the US guidelines, patients with a bicarbonate level of $18 \mathrm{mmol} / \mathrm{L}$ can have mild DKA. This is included to recognize that DKA may be partially treated prior to presentation at the hospital. It should be noted that patients with DKA can have a wide range of acid-base disorders and may have a small anion gap despite increased beta-hydroxybutyrate concentrations [26]. This subset of patients may be erroneously classified as having mild DKA if one was to look for just the anion gap.

For the diagnosis of ketoacidosis, the ADA 2009 guidelines recommend that measurement of ketones by nitroprusside reaction be used because it was more readily available. However, since beta-hydroxybutyrate is the main product of ketogenesis and the nitroprusside reaction does not measure beta-hydroxybutyrate [27], the ADA guidelines suggest measurement of beta-hydroxybutyrate if possible. Further, in the US guidelines, anion gap is used in the diagnostic criteria. Aggressive administration of insulin can cause hyperchloremia and decrease the gap prior to an increase in bicarbonate. Therefore, attention has to be paid to bicarbonate concentrations rather than just the anion gap. The ADA guidelines also recommend the use of arterial $\mathrm{pH}$ but state that venous $\mathrm{pH}$ can also be used [25, 28, 29].

\section{Treatment}

Both documents agree that the primary treatment should be fluid replacement and that the initial fluid replacement of choice is $0.9 \%$ sodium chloride solution. The rates of 
fluid replacement are similar- the US document advocating $15-20 \mathrm{~mL} / \mathrm{kg} / \mathrm{h}(1-1.5 \mathrm{~L})$ in the first hour (regardless of severity) and the UK document $1 \mathrm{~L}$ in each of the first $2 \mathrm{~h}$. Both documents agree that phosphate replacement is not needed as the randomized controlled study by Kitabchi et al. did not show differences in outcomes [30]. The rate of insulin infusion is the same in both documents at 0.1 units $/ \mathrm{kg} / \mathrm{h}$. There are differences in how the insulin infusion rate should be adjusted. The guidelines differ as to the amount and timing of insulin and the use of bicarbonate.

\section{UK Perspective}

The UK guideline recommends adjustment of insulin infusion depending on the rate of fall of glucose $(3.0 \mathrm{mmol} / \mathrm{h}$ [54 mg/dL]) and serum ketones $(0.5 \mathrm{mmol} / \mathrm{h})$ with a corresponding rise in bicarbonate concentration of $3.0 \mathrm{mmol} / \mathrm{L}$. The UK guideline also incorporates the new evidence to show that the continued use of long-acting basal insulin helps to prevent the rebound hyperglycemia seen when the intravenous insulin is stopped [31].

\section{US Perspective}

The grading of the severity of DKA directly translates to the relevant treatment regimen. In the USA, Kitabchi et al. performed pioneering studies in the use of low-dose insulin regimens for the treatment of DKA, e.g., 0.22 units per kilogram (with a subsequent sliding scale dependent on subsequent glucose concentrations) or 0.33 units per kilogram followed by an infusion of 7 units per hour $[12,13]$. A later study by Umpierrez et al. also showed that frequent subcutaneous insulin injections are just as efficacious as intravenous insulin for the treatment of mild-moderate DKA [32]. Subcutaneous insulin injections can more easily be performed in the general medical units rather than the ICU.

For fluid management, the US guideline suggests the use of $0.45 \%$ saline infusion depending on sodium levels. The rate of adjustment of IV insulin differs as well. The US guideline advocates increasing the infusion rate after an hour if the glucose values do not fall by $10 \%$. The UK document does not recommend the use of bicarbonate replacement with the rationale that fluid and insulin replacement alone will be sufficient to raise $\mathrm{pH}$. The US guideline says that bicarbonate should be given when the $\mathrm{pH}$ is $<6.9$ until the $\mathrm{pH}$ is $>7.0$. Even though a prospective randomized study did not show benefit for the use of bicarbonate in severe DKA [33], bicarbonate therapy is recommended when the $\mathrm{pH}$ is $<6.9$ because being acidotic may cause adverse cardiovascular and pulmonary effects [34].

\section{Hyperglycemic Hyperosmolar State}

Unlike DKA, the criteria for diagnosis of hyperglycemic hyperosmolar state (HHS) are not as well defined. It was initially described as a separate entity causing diabetic coma by Dreschfield [35] and Von Frerichs [36]. In the Bradshawe lecture delivered by Dreschfield in 1886, he described three types of diabetic coma. The first one that he described is a gradual coma in older adults (age $>40$ ) and in overweight adults without the characteristic acetone breath or acetone in the urine. After this case, several authors described diabetic coma in which polydipsia and polyuria were accompanied by hyperglycemia but without the characteristic Kussmaul breathing seen in DKA [37-39]. Unlike patients with DKA, there was not a presence of ketones or beta-hydroxybutyrate. The full extent of the metabolic derangements seen with HHS was not fully described till the 1950s [40, 41]. In these papers, the authors reported the severe hyperglycemia accompanied by osmotic diuresis but without ketonuria. They also suggested measurement of electrolytes such as sodium and chloride. After this, Gerich et al. [42] and Arieff and Carroll [43] described HHS further and coined the term hyperglycemic hyperosmolar nonketotic coma (HHNK or HONK). A comprehensive history of HHS was described in full detail in a review by Pasquel and Umpierrez [44].

\section{Diagnosis}

HHS occurs mostly in adults and elderly patients and has a higher mortality than DKA with death occurring in 5-16\% $[45,46]$. The evolution of HHS is over several days to weeks, and the most common presentation is altered mental status $[47,48]$. The UK has separate guidelines for the diagnosis of HHS [17]. Due to the lack of randomized controlled trials for the treatment of HHS, the ADA consensus has combined both DKA and HHS [8]. Both statements recommend the assessment of severity at presentation. However, the UK guidelines give specific data cut points to determine the severity of HHS (Table 2). Both recommend evaluation of precipitating causes.

The unique distinguishing factor in HHS is the absence of ketones or a low ketone production despite an insulinopenic state. In general, glucose levels in HHS are higher than the ones for DKA. Both the UK guidelines and the ADA suggest similar glucose levels to diagnose HHS. The UK guidelines suggest a cutoff value of glucose $>30 \mathrm{mmol} / \mathrm{L}(540 \mathrm{mg} / \mathrm{dL})$, and the ADA consensus statement suggests a cutoff $>33.3 \mathrm{mmol} / \mathrm{L}(600 \mathrm{mg} / \mathrm{dL})$. In addition to hyperglycemia, patients with HHS present with severe dehydration due to the chronic nature of hyperglycemia. Although there are a subset of patients that present with both DKA and HHS, both groups suggest making a diagnosis of HHS when the $\mathrm{pH}$ is greater than 7.3 and the bicarbonate level is greater than 
Table 2 UK vs USA diagnostic criteria for HHS

\begin{tabular}{|c|c|c|c|}
\hline & & UK & USA \\
\hline Hyperglycemia & & $\begin{array}{l}>30 \mathrm{mmol} / \mathrm{L} \\
\quad(540 \mathrm{mg} / \mathrm{dL})\end{array}$ & $\begin{array}{l}>33.3 \mathrm{mmol} / \mathrm{L} \\
\quad(600 \mathrm{mg} / \mathrm{dL})\end{array}$ \\
\hline \multirow[t]{2}{*}{ Hyperosmolarity } & & $>320 \mathrm{mOsm} / \mathrm{kg}$ & $>320 \mathrm{mOsm} / \mathrm{kg}$ \\
\hline & Calculation & $\begin{array}{l}2 \times \mathrm{Na} \\
\quad(\mathrm{mmol} / \mathrm{L})+ \\
\text { glucose } \\
\quad(\mathrm{mmol} / \mathrm{L})+ \\
\text { urea }(\mathrm{mmol} / \mathrm{L})\end{array}$ & $\begin{aligned} 2 \times & \mathrm{Na} \\
& (\mathrm{meQ} / \mathrm{L})+ \\
& \text { glucose } \\
& (\mathrm{mg} / \mathrm{dL}) / 18+ \\
& \text { blood urea } \\
& \text { nitrogen } \\
& (\mathrm{mg} / \mathrm{dL})] / 2.8\end{aligned}$ \\
\hline \multirow[t]{3}{*}{ Lack of acidosis } & Ketones & Low & Low \\
\hline & $\mathrm{pH}$ & $>7.3$ & $>7.3$ \\
\hline & Bicarbonate & $>15 \mathrm{mmol} / \mathrm{L}$ & $>20 \mathrm{mmol} / \mathrm{L}$ \\
\hline $\begin{array}{l}\text { Mental status } \\
\text { changes }\end{array}$ & & Present & Present \\
\hline
\end{tabular}

Adapted from [7, 8]

$15 \mathrm{mmol} / \mathrm{L}$ (UK guidelines) and $>20 \mathrm{mmol} / \mathrm{L}$ for ADA consensus statement along with minimal ketonemia. The differences in the diagnosis, although minimal, lie in the calculation of osmolality and assessment of severity. The differences are outlined in Table 2.

\section{UK Perspective}

Both the US and UK guidelines use the cutoff of $320 \mathrm{mOsm} / \mathrm{kg}$ for the diagnosis of serum osmolality. This value is based on studies that show that mental status changes occur with serum osmolality $>320 \mathrm{mOsm} / \mathrm{kg}$. Osmolality is calculated by the formula $[2 \times$ measured $\mathrm{Na}(\mathrm{meQ} / \mathrm{L})+$ glucose $(\mathrm{mg} / \mathrm{dL}) / 18$ + blood urea nitrogen $(\mathrm{mg} / \mathrm{dL})] / 2.8]$ or $[2 \times$ measured $\mathrm{Na}(\mathrm{mmol} / \mathrm{L})+$ glucose $(\mathrm{mmol} / \mathrm{L})+[$ urea $(\mathrm{mmol} / \mathrm{L})]$. Blood urea nitrogen is not an effective osmolyte as it can cross membranes without an osmotic effect. The UK guidelines suggest several ways of calculating serum osmolality, which do not include blood urea nitrogen levels. However, due to provider attitudes, it is suggested that it is included in the calculation.

\section{US Perspective}

Because of its ability to pass freely across plasma membranes, the ADA guidelines recommend calculation of serum osmolality without the inclusion of blood urea nitrogen. Therefore, the patients diagnosed with HHS as per ADA consensus are likely to be more dehydrated prior to receiving intervention for HHS. Again, whether this results in different outcomes compared to the UK guidelines is unclear.

\section{Treatment}

The treatment of HHS, as with DKA, involves correction of dehydration and lowering glucose. Both guidelines recommend careful monitoring of serum osmolality in order to avoid complications of rapid overcorrection. Both guidelines recommend initiation of IV fluids with approximately 11 of $0.9 \%$ saline and aggressive correction of dehydration till osmolality stops declining. Both guidelines suggest maintaining glucose concentrations of $13.9-16.7 \mathrm{mmol} / \mathrm{L}$ $(250-300 \mathrm{mg} / \mathrm{dL}$ in the USA) and $10-15 \mathrm{mmol} / \mathrm{L}(180$ $270 \mathrm{mg} / \mathrm{dL}$ in the UK). Patients with HHS have depleted potassium stores although less than that in DKA. Both the UK and the ADA consensus statements suggest giving potassium if the concentration is less than $3.3 \mathrm{meQ} / \mathrm{L}$ ( $3.3 \mathrm{mmol} / \mathrm{L}$ ) and to not replace potassium if the concentration is greater than $5.5 \mathrm{meQ} / \mathrm{L}(5.5 \mathrm{mmol} / \mathrm{L})[8,17]$. The differences in the guidelines are with choice of fluid with respect to sodium concentrations and timing of insulin initiation.

\section{UK Perspective}

The UK guidelines recommend initial treatment with 11 of $0.9 \%$ saline for the first hour with subsequent adjustment of rate and fluids depending on changes in osmolality (3-8 $\mathrm{mOsmol} / \mathrm{kg} / \mathrm{h}$ ) after the first hour for $6 \mathrm{~h}$ after presentation with a decrease in glucose of $5 \mathrm{mmol} / \mathrm{L} / \mathrm{h}(90 \mathrm{mg} / \mathrm{dL} / \mathrm{h})$. The use of $0.45 \%$ saline is not routinely recommended. However, the guidelines do make an exception for the use of $0.45 \%$ saline when osmolality does not decline despite adequate fluid administration. Intravenous insulin should be started at weight-based, fixed-rate intravenous insulin at $0.05 \mathrm{U} / \mathrm{kg} / \mathrm{h}$ once glucose concentrations stop declining with fluid resuscitation when glucose concentrations stop declining with fluid resuscitation.

\section{US Perspective}

The ADA guidelines recommend initial treatment with 1$1.5 \mathrm{~L}$ of $0.9 \%$ saline. Unlike the UK, they recommend that $0.45 \%$ saline be administered when sodium levels are elevated. Recommendations are made to change fluids according to osmolality. In general, the recommendation is to start intravenous insulin dose at $0.1 \mathrm{U} / \mathrm{kg} / \mathrm{h}$ once osmolality stops declining. They also suggest doubling the insulin dose if glucose is not falling by $2.8-3.9 \mathrm{mmol} / \mathrm{L} / \mathrm{h}$ $(50-70 \mathrm{mg} / \mathrm{dL} / \mathrm{h})$. Once glucose concentrations of 13.9 $16.7 \mathrm{mmol} / \mathrm{L}(250-300 \mathrm{mg} / \mathrm{dL})$ are achieved, the ADA 
guidelines recommend decreasing insulin dose to $0.02-$ $0.05 \mathrm{U} / \mathrm{kg} / \mathrm{h}$.

\section{Conclusions}

In summary, with respect to the management of DKA and HHS, there are wide areas of overlap between the US and UK guidelines. However, there are also equally wide areas where opinions diverge. It is these areas where there are differences of opinion that illustrate the lack of good research to help guide the best treatments for patients. Ultimately, it is fluid, insulin, and potassium replacements, but the questions remain: how much and how fast? For example, there remain questions on which fluid should be used [49] and whether the use of bicarbonate alters the outcomes in those with low $\mathrm{pH}$. Furthermore, more work needs to be done to assess how DKA is diagnosed. In the UK and elsewhere, chloride measurements are not readily available, and therefore, it is impossible to calculate the anion gap. Therefore, if an anion gap cannot be calculated, how do institutions grade severity? Is severity therefore incorrectly based on the presence of 1 or 2 of the $\mathrm{D}$, the $\mathrm{K}$, and the $\mathrm{A}$ ? If that is the case, then this puts the classification of DKA at risk, and any research using DKA needs to ensure standardization of diagnosis and assessment of severity. Further areas of research also include prospective trial of whether different severities of DKA require different treatments and whether this affects outcomes. There are also no prospective trials for the treatment of HHS. Data is also lacking as to the physiologic basis and outcomes of patients that present with combined DKA and HHS. Finally, both guidelines need to be updated on the recognition and treatment of euglycemic DKA.

Acknowledgments Ketan K. Dhatariya is an employee of the UK National Health Service.

\section{Compliance with Ethical Standards}

Conflict of Interest Ketan K. Dhatariya is the lead author of the Joint British Diabetes Societies Guideline for the management of DKA. He is also on the Clinical Endpoint Adjudication Committee for the Sotagliflozin trials run by Lexicon Pharmaceuticals.

Priyathama Vellanki has received consulting fees from Merck \& Co.

Human and Animal Rights and Informed Consent This article does not contain any studies with human or animal subjects performed by any of the authors.

Open Access This article is distributed under the terms of the Creative Commons Attribution 4.0 International License (http:// creativecommons.org/licenses/by/4.0/), which permits unrestricted use, distribution, and reproduction in any medium, provided you give appropriate credit to the original author(s) and the source, provide a link to the Creative Commons license, and indicate if changes were made.

\section{References}

Papers of particular interest, published recently, have been highlighted as:

- Of importance,

- Of major importance

1. Kim S. Burden of hospitalizations primarily due to uncontrolled diabetes. Diabetes Care. 2007;30:1281-2.

2. Health and Social Care Information Centre. National Diabetes Inpatient Audit (NaDIA)-2015. http://www.hscic.gov.uk/ catalogue/PUB20206. 2016. Last $3^{\text {rd }}$ Accessed Feb 2017.

3. Root HF. The use of insulin and the abuse of glucose in the treatment of diabetic coma. JAMA. 1945;127:557-64.

4. Black AB, Malins JM. Diabetic ketoacidosis. A comparison of results or orthodox and intensive methods of treatment based on 170 consecutive cases. Lancet. 1949;253:56-9.

5. Gibb FW, Teoh WL, Graham J, Lockman KA. Risk of death following admission to a UK hospital with diabetic ketoacidosis. Diabetologia. 2016;59:2082-7. This paper from the UK describes the risk factors for death following admission due to DKA. Mortality was increased in the young, socially disadvantaged with poor glycaemic control.

6. Mays JA, Jackson KL, Derby TA, Behrens JJ, Goel S, Molitch ME, Kho AN, Wallia A. An evaluation of recurrent diabetic ketoacidosis, fragmentation of care, and mortality across Chicago, Illinois. Diabetes Care. 2016;39:1671-6. This paper from the USA describes the risk factors for recurrent DKA and mortality. These included fragmentation of care - i.e. admissions to numerous hospitals.

7. Savage MW, Dhatariya KK, Kilvert A, Rayman G, Rees JA, Courtney CH, Hilton L, Dyer PH, Hamersley MS, for the Joint British Diabetes Societies. Joint British Diabetes Societies guideline for the management of diabetic ketoacidosis. Diabetic Med. 2011;28:508-15.

8. Kitabchi AE, Umpierrez GE, Miles JM, Fisher JN. Hyperglycemic crises in adult patients with diabetes. Diabetes Care. 2009;32:133543.

9. Sonksen PH, Tompkins CV, Nabarro JD. Growth-hormone and cortisol responses to insulin infusion in patients with diabetes mellitus. Lancet. 1972;300:155-60.

10. Kidson W, Casey J, Kraegen E, Lazarus L. Treatment of severe diabetes mellitus by insulin infusion. Br. Med. J. 1974;2:691-4.

11. Page MM, Alberti KG, Greenwood R, Gumaa KA, Hockaday TD, Lowy C, Nabarro JD, Pyke DA, Sonksen PH, Watkins PJ, West TE. Treatment of diabetic coma with continuous low-dose infusion of insulin. Br. Med. J. 1974;2:687-90.

12. Kitabchi AE, Ayyagari V, Guerra SM. The efficacy of low-dose versus conventional therapy of insulin for treatment of diabetic ketoacidosis. Ann. Intern. Med. 1976;84:633-8.

13. Fisher JN, Shahshahani MN, Kitabchi AE. Diabetic ketoacidosis: low-dose insulin therapy by various routes. N Eng J Med. 1977;297:238-41.

14. Carroll P, Matz R. Uncontrolled diabetes mellitus in adults: experience in treating diabetic ketoacidosis and hyperosmolar nonketotic coma with low-dose insulin and a uniform treatment regimen. Diabetes Care. 1983;6:579-85.

15. Umpierrez GE. Abbas E. Kitabchi, PhD, MD: An exemplary mentor and clinical researcher. Diabetes Care. 2016;39:333-6.

16. Dhatariya, K, Savage, M, Claydon, A, Dyer, P, Evans, P, Khan, A, Kilvert, A, Leech, N, Levy, N, Rayman, G, Rees, A, and SinclairHammersley, M. Joint British Diabetes Societies Inpatient Care Group. The management of diabetic ketoacidosis in adults. Second Edition. Update: September 2013. http://www. 
diabetologists-abcd.org.uk/JBDS/JBDS_IP_DKA_Adults Revised.pdf. 2013. Last 3rd Accessed Feb 2017

17. Scott A, on behalf of the Joint British Diabetes Societies (JBDS) for Inpatient Care. Management of hyperosmolar hyperglycaemic state in adults with diabetes. Diabetic Med. 2015;32:714-24.

18. Munro JF, Campbell IW, McCuish AC, Duncan JP. Euglycaemic diabetic ketoacidosis. BMJ. 1973;2:578-80.

19. Peters AL, Buschur EO, Buse JB, Cohan P, Diner JC, Hirsch IB. Euglycemic diabetic ketoacidosis: a potential complication of treatment with sodium-glucose cotransporter 2 inhibition. Diabetes Care. 2015;38:1687-93. This paper outlines the increased risk of developing DKA in patients on SLGT-2 inhibitors.

20. Guo R-X, Yang L-Z, Li L-X, Zhao X-P. Diabetic ketoacidosis in pregnancy tends to occur at lower blood glucose levels: case-control study and a case report of euglycemic diabetic ketoacidosis in pregnancy. J Obstet Gynaecol Res. 2008;34:324-30.

21.• Dhatariya KK, Nunney I, Higgins K, Sampson MJ, Iceton G. A national survey of the management of diabetic ketoacidosis in the UK in 2014. Diabetic Med. 2016;33(2):252-60. This large national study on the management of DKA from the UK showed that care was very good whilst patients were in the emergency room, but care processes subsequently deteriorated. A significant proportion of patients developed hypokalaemia or hypoglycaemia.

22. Herrington WG, Nye HJ, Hammersley MS, Watkinson PJ. Are arterial and venous samples clinically equivalent for the estimation of $\mathrm{pH}$, serum bicarbonate and potassium concentration in critically ill patients? Diabetic Med. 2012;29:32-5.

23. Gokel Y, Paydas S, Koseoglu Z, Alparslan N, Seydaoglu G. Comparison of blood gas and acid-base measurements in arterial and venous blood samples in patients with uremic acidosis and diabetic ketoacidosis in the emergency room. Am J Nephrol. 2000;20:319-23.

24. Ma OJ, Rush MD, Godfrey MM, Gaddis G. Arterial blood gas results rarely influence emergency physician management of patients with suspected diabetic ketoacidosis. Acad Emerg Med. 2003;10:836-41.

25. Malatesha G, Singh NK, Bharija A, Rehani B, Goel A. Comparison of arterial and venous $\mathrm{pH}$, bicarbonate, $\mathrm{Pco} 2$ and $\mathrm{Po} 2$ in initial emergency department assessment. Emerg. Med. J. 2007;24:56971.

26. Adrogue HJ, Wilson H, Boyd AE, Suki WN, Eknoyan G. Plasma acid-base patterns in diabetic ketoacidosis. N Eng J Med. 1982;307: 1603-10.

27. Dhatariya K: Blood ketones - measurement, interpretation, limitations and utility in the management of diabetic ketoacidosis. Rev Diabet Stud. 2017. doi:10.1900/RDS.2016.13.217.

28. Kelly A-M, Mcalpine R, Kyle E. Venous $p H$ can safely replace arterial $\mathrm{pH}$ in the initial evaluation of patients in the emergency department. Emerg. Med. J. 2001;18:340-2.

29. Middleton P, Kelly A-M, Brown J, Robertson M. Agreement between arterial and central venous values for $\mathrm{pH}$, bicarbonate, base excess, and lactate. Emerg Med J. 2006;23:622-4.
30. Fisher JN, Kitabchi AE. A randomized study of phosphate therapy in the treatment of diabetic ketoacidosis. J. Clin. Endocrinol. Metab. 1983;57:177-80.

31. Hsia E, Seggelke S, Gibbs J, Hawkins RM, Cohlmia E, Rasouli N, Wang C, Kam I, Draznin B. Subcutaneous administration of glargine to diabetic patients receiving insulin infusion prevents rebound hyperglycemia. J Clin Endocrinol Metab. 2012;97:3132-7.

32. Umpierrez GE, Latif K, Stoever J, Cuervo R, Park L, Freire AX, Kitabchi AE. Efficacy of subcutaneous insulin lispro versus continuous intravenous regular insulin for the treatment of patients with diabetic ketoacidosis. Am J Med. 2004;117:291-6.

33. Morris LR, Murphy MB, Kitabchi AE. Bicarbonate therapy in severe diabetic ketoacidosis. Ann Intern Med. 1986;105:836-40.

34. Mitchell JH, Wildenthal K, Johnson RL. The effects of acid-base disturbances on cardiovascular and pulmonary function. Kidney Int. 1972;1:375-89.

35. Dreschfeld J. The Bradshawe lecture on diabetic coma. Br. Med. J. 1886;2:358-63.

36. von Frerichs F: Uber den diabetes. August Hirschwald, Berlin 113: 1884.

37. Rosenbloom J. A form of diabetic coma, not due to the acetone bodies. New York Medical Journal. 1915;102:294-6.

38. Marble A, Root HF, White P. Diabetic coma. N. Eng. J. Med. 1935;212:288-97.

39. Root HF, Leech R. Diabetic coma and hyperglycemic stupor compared. Med Clin North Am. 1946;30:1115.

40. De Graeff J, Lips JB. Hypernatraemia in diabetes mellitus. Acta Med Scand. 2016;1957:1-71.

41. Sament S, Schwartz MB. Severe diabetic stupor without ketosis. S Afr Med J. 1957;31:893-4.

42. Gerich JE, Martin MM, Recant L. Clinical and metabolic characteristics of hyperosmolar nonketotic coma. Diabetes. 1971;20:228 38.

43. Arieff AI, Carroll HJ. Hyperosmolar nonketotic coma with hyperglycemia: abnormalities of lipid and carbohydrate metabolism. Metab Clin Exp. 1971;20:529-38.

44. Pasquel FJ, Umpierrez GE. Hyperosmolar hyperglycemic state: a historic review of the clinical presentation, diagnosis, and treatment. Diabetes Care. 2014;37:3124-31.

45. Fadini GP, De Kreutzenberg SV, Rigato M, Brocco S, Marchesan M, Tiengo A, Avogaro A. Characteristics and outcomes of the hyperglycemic hyperosmolar non-ketotic syndrome in a cohort of 51 consecutive cases at a single center. Diabetes Res Clin Pract. 2011;94:172-9.

46. Pinies JA, Cairo G, Gaztambide S, Vazquez JA. Course and prognosis of 132 patients with diabetic non ketotic hyperosmolar state. Diabete Metab. 1994;20:43-8.

47. Wachtel TJ, Tetu-Mouradijian LM, Goldman DL, Ellis SE, O'Sullivan PS. Hyperosmolarity and acidosis in diabetes mellitus: a three-year experience in Rhode Island. J Gen Intern Med. 1991;6: 495-502.

48. Wachtel TJ, Silliman RA, Lamberton P. Prognostic factors in the diabetic hyperosmolar state. J Am Geriatr Soc. 1987;35:737-41.

49. Dhatariya KK. Diabetic ketoacidosis. Br Med J. 2007;334:1284-5. 